\title{
Research on the Development Strategy of Cultural and Creative Products Based on Regional Culture
}

\author{
Jiani Liu \\ Hainan College of Vocation and Technique
}

Keywords: regional culture; cultural and creative products; development strategy

\begin{abstract}
The development and utilization of cultural and creative products can not only fully display the local regional cultural characteristics, but also promote local economic development. Based on the regional culture, this paper proposes the development strategy of cultural and creative products, laying a good foundation for the development and development of cultural and creative products.
\end{abstract}

\section{Introduction}

The rapid and rapid development of China's economy has prompted China's development momentum in many aspects to become better and better, and has received widespread attention and attention. At the same time, China's vast territory, history and culture have a history of 5,000 years of development, and today, there are still many cities and regions with a rich cultural heritage. In particular, many small towns have been completely preserved, and many traditional handicrafts and crafts have been correspondingly passed down and developed. Due to the vast territory of China, different regions have their own unique culture in the process of development. There are many industries that are driven and influenced by local culture. Especially in the context of the rapid development of the current economy, people's ideology has undergone a certain transformation, and at the same time, their horizons have become more and more broad. They are no longer simply limited to the physical form, but gradually focus on the spiritual world. In pursuit, this can also be seen as a manifestation of regional culture.

\section{Emotional design of cultural and creative products based on regional culture}

In the process of development and specific promotion of cultural and creative products, in order to achieve good promotion and publicity, we must be aware of the theme of cultural and creative products. Cultural and creative products usually refer to the products produced by the combination of culture and creativity. Although this type of products must have certain innovations and ideas, culture still occupies a central position. In the process of development, cultural and creative products must pay attention to the basic part of the product is the product, and this can also be seen as a form of culture, more expressed in the form of physical expression. When analyzing cultural and creative products, it is found that if we analyze and study it from the perspective of implementation, then the corresponding cultural creative products usually only use the elements of one part as reference. .At the same time, it is also possible to combine the cultural situation with the cultural background to achieve product design ${ }^{[1]}$.In the process of design and development, cultural and creative products generally regard culture as the basic link, and take the initiative as the basic rule.In this way, effective implementation in practice can not only make rational use of professional knowledge, but also deepen understanding and understanding of culture. It can be seen that in the process of designing cultural and creative products, it is necessary to effectively integrate with the regional characteristic culture, so as to be able to design and develop cultural and creative products that meet people's spiritual needs.

Culture has been widely mentioned in recent years. After thousands of years of development, culture has become more and more profound. However, for many young people, many cultures are relatively unfamiliar, especially with many regional cultures, and many people have never heard of $\mathrm{it}^{[2]}$. This is not only difficult to achieve the inheritance and development of culture, but also has a 
serious restrictive impact on the development of regional culture. Therefore, in recent years, the combination of culture and popular expressions has been effectively combined. It is like clothing, and the fashion trends and popular characteristics of clothing will change with the changes of the times and the development of society. In this context, in order to fully exert its cultural characteristics in practice, it is necessary to innovate and effectively integrate with the development background and characteristics of the times. When combined with the actual situation, it is found that for the development of modern society, various types of products, no matter the type or style, are more and more, and the progress and development speed of technology in it is also faster. Therefore, in this context, it is not a good choice trend ${ }^{[3]}$ to truly develop and utilize products from a functional perspective. Since good products are always replaced, only emotions and integration in products cannot be eliminated as time goes by. In fact, "creative" can be seen as a sense of identity that comes from being touched. The most obvious difference in the design and development of cultural and creative products is the difference in the design process. In the process of design and application, cultural and creative products should combine the influence of culture in it, and integrate it into the design concept to realize the design from the cultural point of view. Culture is the unique way of life of a local group of people, which means that culture and people have very deep feelings with each other. Ideas don't come out casually. Ideas may be something that people remember when they are young, or some experiences in the local area when they were young.

In general, cultural creative products in the process of design and development, their own ideas, in fact, more refers to modern people's "experience" of traditional culture or traditional life. It is not just commodities that are promoted or even sold, but more of an emotion and a feeling. For example, Li Jin, a unique culture in Hainan, can be regarded as a "wonderful" in the Chinese textile art industry. Li Jin is very delicate in the production process, and at the same time, it is also bright in color and romantic. In the design and production process, the patterns and patterns involved will be very beautiful, and will also be combined with some birds and beasts, flowers and plants, etc., in the textile or in the dyeing and embroidery, etc., can reflect the local cultural characteristics. In the analysis of the local Li Jin culture, it was found that most of the local Lijin were mainly woven, weaved and dyed, and the use of embroidery was relatively small ${ }^{[4]}$. When using dyes, it is common to enter some mountainous areas to pick some wild plants as raw materials for dyeing. The color of these dyeing materials is relatively bright, and it is not easy to appear fading. It is precisely because of this regional cultural characteristic that many local Li people in Hainan will combine with their own love to create various types of weaving. Dyeing technology.As shown in Figure 1.

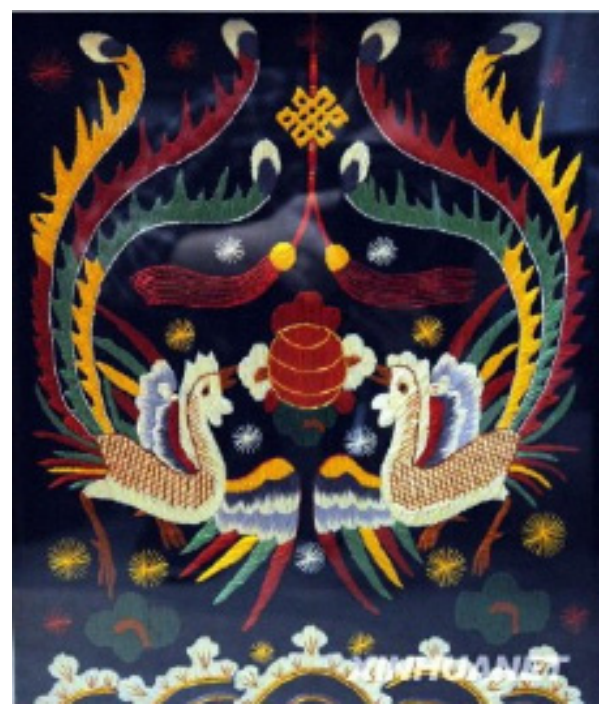

Figure 1 Schematic diagram of Li Jin weaving

It can be seen that $\mathrm{Li}$ Jin is a unique regional characteristic culture in Hainan. In order to promote this culture, local people combine it with costumes to produce costumes with modern fashion style ${ }^{[5]}$.As shown in Figure 2 and Figure 3. This will not only help to promote the local cultural characteristics of the region, but also promote the effective growth of local economic benefits. 


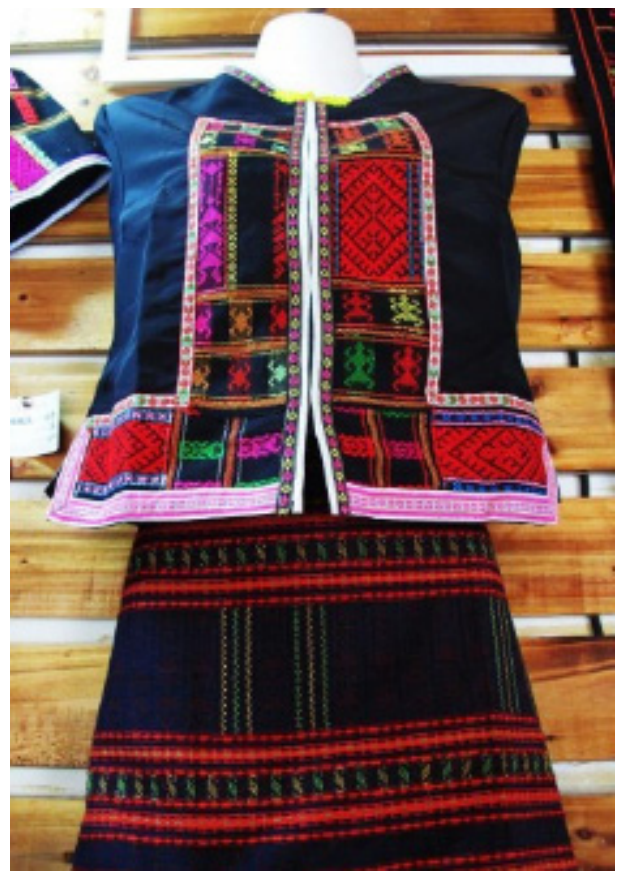

Figure 2 Fashion produced by Li Jin (1)

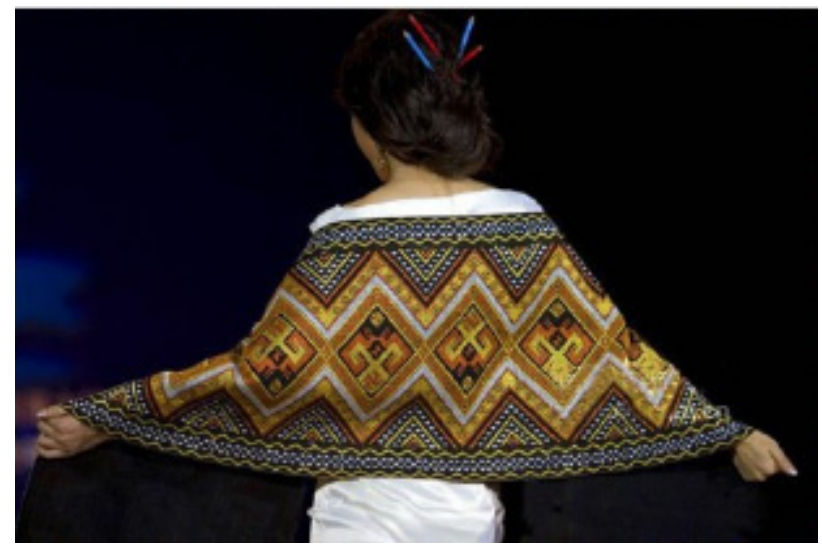

Figure 3 Fashion produced by Li Jin (2)

\section{Innovative design of cultural and creative products based on regional culture}

Wenchuang products mainly refer to the effective combination of culture and creative products, and the core can be regarded as "commodities" to some extent. At the same time, the essence of goods is the transaction, the commodity as the core element, and the additional role and value of the cultural attribute in it should be fully exerted. In fact, when many people understand and analyze Wenchuang products, the more common expressions and design concepts are actually "storytelling"."Storytelling" is an indispensable part of the design and development of Wenchuang products, but it is not unique.

In fact, China's development history in design is not very long. In the early days, China hired more professional designers from abroad. Due to the influence of many Western design concepts, until now, many designers in China still admire foreigners. However, with the development of the economy and the continuous exploration of culture, many local designers in China have gradually realized the importance of local culture in the design process. Although many designers have gradually incorporated some connotations and traditions with regional cultural characteristics into the design works in the design process, they have not deeply explored many regional cultural characteristics. There are a lot of cultural details embodied in the fur, and even some of the content of the understanding is basically wrong. The reference to cultural elements must have an in-depth 
understanding of it so that the scientific and rational design and utilization of cultural and creative products can be realized. For example, in many design works, only some elements with Chinese cultural characteristics can be seen, but no innovation can be seen among these elements. In fact, in the analysis of the actual situation, it is found that among these regional cultural elements, in addition to some visual totems or other images, there is a lack of inner soul ${ }^{[6]}$.In particular, there are many cultural and creative products in the design and application process, often there will be such a routine of copying and pasting, which is clearly a cultural feature of different regions, but the overall feeling is the same.

For example, when designing regional cultural and creative products, it is appropriate to integrate some local traditional regional cultures, and at the same time, effectively combine the functions and scenes of the products themselves in use, so that for products, Give more meaning and connotation in it. For example, Hainan's local arcade culture is shown in Figure 4.

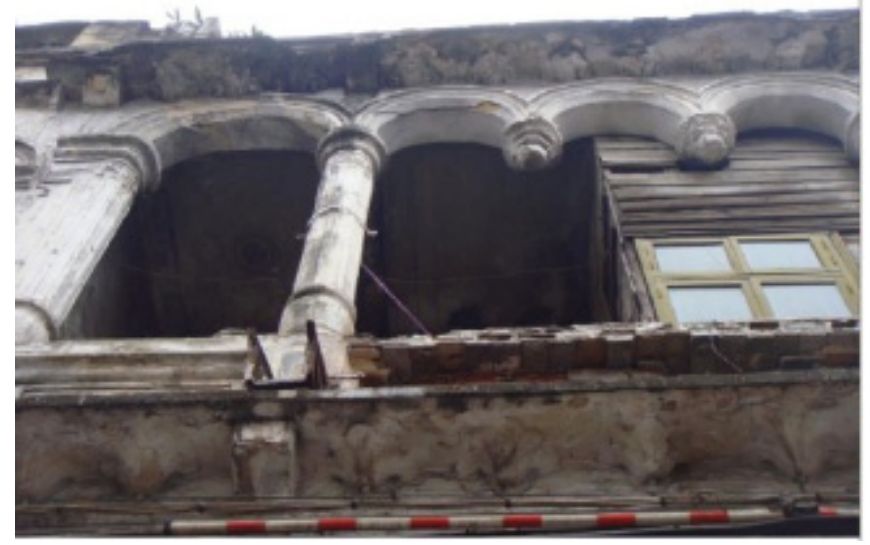

Figure 4 Schematic diagram of Hainan arcade culture

In fact, there is no similar souvenir in Hainan's arcade culture. However, the embodiment of the arcade culture can be combined with other different types of products, such as function or appearance, to fully display this cultural feature. For example, it is possible to print the style of the arcade style on some daily necessities such as cups and tableware, so that not only the characteristics of the Hainan arcade culture can be fully displayed, but also the reasonable promotion of the local arcade culture can be realized. As shown in Figure 5.

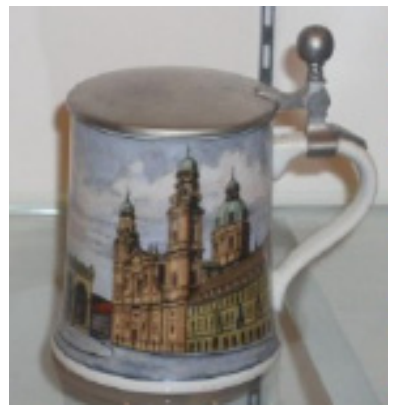

Figure 5 Schematic diagram of the promotion design of Hainan arcade culture on the cup

\section{Combination of cultural and creative product traditions and modern concepts in the context of regional culture}

When designing and developing the creative products of the text, it is necessary to follow the prescribed standards and design processes, so that not only good design effects, but also targeted promotion can be achieved. In the specific operation process, a series of preparatory work must be done in advance, especially to ensure the in-depth development of market research work. On this basis, the corresponding concept can be gradually generated, so that not only the planning and design of the product can be realized, but also the commercialization characteristics of the 
Wenchuang product itself can be fully exerted. In the end, it is effectively combined with local regional cultural characteristics to form a product with brand effect.

No matter what region is in the development process, it has its own unique traditional cultural characteristics. Therefore, in this context, for the designers, it is necessary to carry out in-depth excavation of the local regional cultural characteristics, so that not only can the understanding and understanding of the local cultural characteristics be realized, but also through the observation and analysis of the entire region. You can find new breakthrough directions. In the past design and development thinking process, it is common to think that tradition or something with regional cultural characteristics are old and outdated. In fact, the effective combination of these traditions and contemporary design concepts not only allows people to have a deeper understanding and understanding of traditional culture, but also can promote the promotion and promotion of local regional cultural characteristics ${ }^{[7]}$.For the design and excavation of regional cultural and creative products, in addition to establishing good cooperative relations with some well-known designers, we can also establish certain cooperative relations with enterprises. The fundamental purpose of this is to promote the effective promotion and implementation of the regional cultural and creative industries through the operation and promotion of enterprises. This can be seen not only as a new promotion model that cooperates with enterprises, but also through the effective implementation in this way, it can construct and implement new brands in line with urban development in practice. The promotion and development model and the implementation in practice do not only refer to some single products, but from the practical point of view, from the perspective of product lines, to achieve the driving of the industry, so that In practice, the overall improvement of the level of regional cultural development is achieved.

\section{Conclusion}

Cultural and creative industries, products in the design and development process, although creativity has a very important impact and role, but culture has always been the foundation, core and focus. China itself is a big country with a very rich cultural history. Therefore, from the perspective of regional culture, it is of substantial significance to realize the development and promotion of cultural and creative products.

\section{References}

[1] Wu Yifan. Research on the renovation design strategy of Xiamen old city based on cultural planning [j]. China Real Estate, 2019 (15): 54-60.

[2] Tu Wei, Zheng Jie. Cultural and Creative Product Development Strategy of Intangible Cultural Heritage Changle Story Society [j]. Packaging Engineering, 2019, 40 (10): 119-124.

[3] Shao Yizhen, Liang Xinyue. Research on the Development of Tianjin Tourism Economy_-Taking Wenchuang Tourism of Tianjin Regional Museum as an Example [j]. Tianjin Economics, 2019(05): 19-23.

[4] An Yongna, Li Jinhong. Research on the Countermeasure of Building the National Culture Pillar Industry in Southeastern Guizhou—Based on swot Matrix Analysis[j]. Popular Literature, 2019(09):241-242.

[5] Zhang Rong. Research on the Development Strategy of Cultural and Creative Products in Dongguan Region_-Taking the Village of Nanshe as an Example [j]. Art Science and Technology, 2019, 32(05): 35-36.

[6] Rong Jinjin, Fang Xin. Research on the development strategy of local traditional craft ip cultural products under the cross-border background [j]. Art Science and Technology, 2019, 32 (05): 55-56. 
[7] Li Jie, Kuang Rui. Research on the Design of Cultural and Creative Products Based on the Protection of the Intangible Cultural Heritage of the Yi Nationality_-Taking the Traditional Embroidery Products of Ganluo in Liangshan Prefecture as an Example [j]. Research on Heritage and Protection, 2019, 4(04) :91-94. 